حث نباتات الكلغان Syllibium marianum بحامض السليسيلك و الاسيتايل ساليسليك لمقاومة مرض البياض ألاقيقي

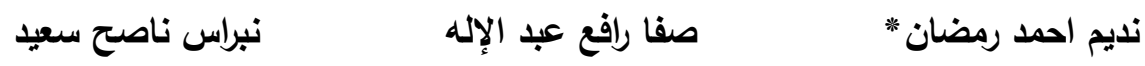

$$
\begin{aligned}
& \text { قسم علوم الحياة/ كلية العلوم/ جامعة الموصل علاله }
\end{aligned}
$$

*E.mail: nadeem.ramadan53@yahoo.com

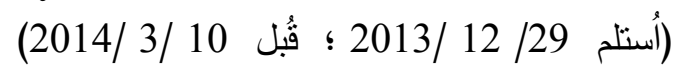

\title{
الملخص
}

اظهر الفحص ألمجهري أن المسبب لمرض البياض ألدقيقي على الكلغان هو الفطر Erysiphe cichoracaerum وتبدأ الأعراض بالظهور في منتصف شهر آذار. تتشير النتائج إلى أن رش النباتات بمبيد النيم مرتين(5\%) لم يكن له تأثنير في نسبة

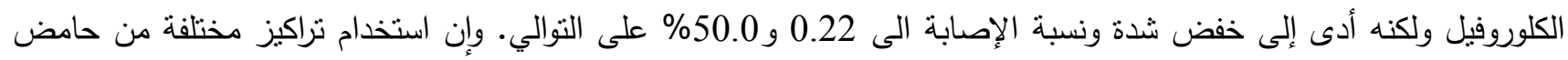
الساليسيليك (SA) والاسيتايل ساليسليك (ASA) أدت إلى زيادة في الوزن الطري والجاف وارتفاع النباتات، وسبب التركيز 1 ملي مول /ASA رشة واحدة إلى زيادة الوزن الطري إلى 10.9غم واختلف الوزن الجاف معنويا عن بقية المعاملات عدا التركيز املي مول AS/ أشة واحدة.

إن أفضل تركيز أدى إلى زيادة نسبة الكلوروفيل في النباتات المصابة بمرض البياض ألدقيقي هو 5 ملي مول SA / رشة

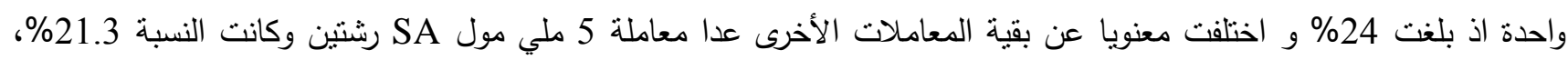

وكان التركيز 5 ملي مول SA أفضل في حث المقاومة مما أدى إلى خفض شدة الإصابة إلى 0.2 وبنسبة انخفاض 95.54 و 95. وجد أن نباتات الكلغان المعاملة رشا بحامض الساليسليك أدى إلى زيادة نشاط أنزيم البيروكسيديز في أوراق نباتات الكلغان التي رشت مرتين بحامض ASA وبالتركيز 5 ملي مول(0.089) وبنسبة زيادة بلغت

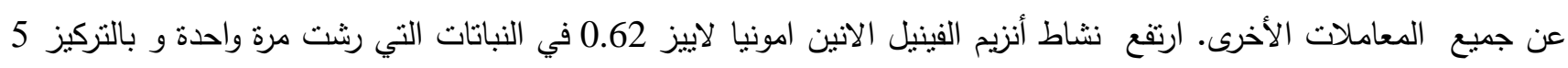

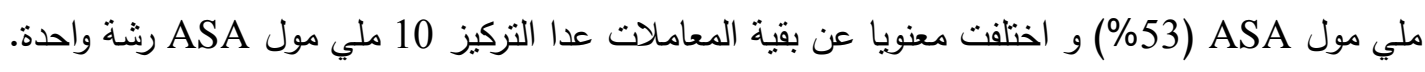
الكلمات الدالة: حامض الساليسليك ،الاسيتايل ساليسليك، حث المقاومة الجهازية، الأنزيمات.

\section{Salicylic Acid and Acetylsalicylic Induced Resistance to Powdery Mildew Disease of Milk thistle (Syllibium marianum)}

Nadeem A. Ramadan*

Department of Biology/ College of Science/ University of Mosul

Nebras N. Saaed

\section{ABSTRACT}

Microscopic examination showed that Erysiphe cichoracaerum is the causal agent of Milk thistle powdery mildew and its symptoms begin to appear in the middle of March.

Plants sprayed with Neem (5\%) had no effect on the percentage of chlorophyll, but reduced the severity percentage infection to $2.2,50.0 \%$ respectively. The use of different concentrations of salicylic acid (SA) acetylsalicylic acid (ASA) led to an increase in wet and dry weight and higher plants hieght. One spray with 1 mmole ASA increased the wet weight to10.9 g. In the meantime, the dry weight differed significantly from other treatments except of 1 mmole SA once spray. 
The better concentration was (24\%) for increasing the percentage of chlorophyll in infected plants with powdery mildew was observed with 5 mmole SA once spray and significantly different from the rest of the treatments other than $5 \mathrm{mmol}$ SA sprayed twice which was $21 \%$. The concentration of $1 \mathrm{mmol}$. SA also was found the best in inducing resistance resulting in a reduction of the infection severity to 0.2 and percentage of infection severity to $95 \%$.

Spraying of Milk thistle plants with SA increased the activity of peroxidase enzyme $(60 \%)$ in plants sprayed twice with SA 5 m mole (0.089) comparing to the control (0.053).

Also, the enzyme activity of phenylalanine ammonia lyase was increased $(0.618)$ in plants sprayed twice with 5 mmole SA (53\%) and hence significantly different from other treatments other than SA 10 mmole sprayed twice.

Keywords: Salicylic acid, Actyl salicylic acid, Induced systemic resistance, Enzymes.

\section{المقدمة}

تعود نباتات الكلغان(Milk thistle) الى العائلة المركبة Asteraceae، ولهذا النبات أهية طبية لاحتواء بذوره على العديد من المركبات الفلافينية التي تسمى معقدات سليمارين (Silymarin-complex) وهو خليط معقد من الفينولات و التي لوني لهوني

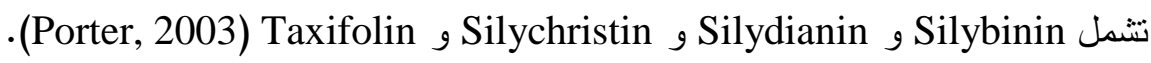
يستوطن مرض البياض ألدقيقي في المحافظات الثمالية من العراق و يصيب العديد من الدحاصيل الحقلية و البستانية و الأدغال و تصاب نباتات الكلغان بمرض البياض ألدقيقي المنسبب عن فطر E. cichoracaerum ابتدأ من النصف الأول لنهر آذار (الكوراني، 2006).

ترتبط مقاومة أمراض النبات بنراكم الأنزيمات والمضادات الحيوية والمثنطات ويمكن حث المقاومة الجهازية للعائل النباتي

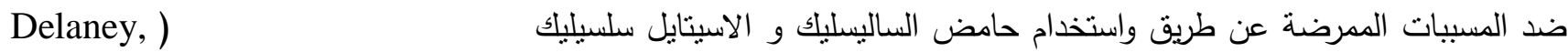
Maleck et al., 2000) ون مامض الساليسيليك (الحامض ألصفصافي أو حامض الصفصاف) هو حامض كربوكسيلي أروماتي تركيبه الكيميائي (C6H4(OH)COOH) عديم اللون بستخلص طبيعيا من بعض النباتات كالصفصاف الأبيض وإكليلية

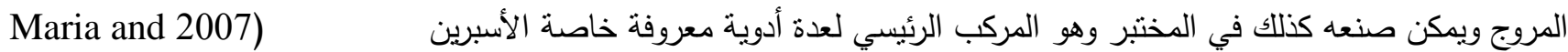
.(Martínez-Merino, اثشارت العديد من الدراسات الى التاثير المباشر لمستخلص نباتات وثمار النيم في الآفات و مسبيات امراض النبات

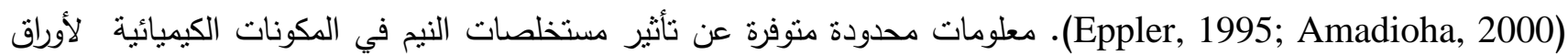
النبانات و حث المقاومة ضد مسببات الامراض. وجد (Singh and Prithiviraj, 1997). ان النيم حث مقاومة نباتات البزاليا ضد البياض الدقيقي المنسبب عن فطر Erysiphe pisi. تهدف الدراسة الحالية إلى حث المقاومة المكتسبة في نباتات الكلغان ضد الفطر المسبب لمرض البياض ألدقيقي باستخدام

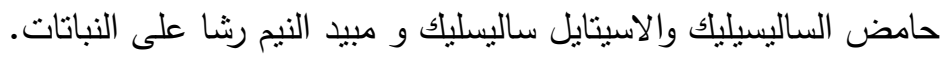

\section{المواد وطرائق العمل}

جمعت نباتات الكلغان من حقول كلية الزراعة و الغابات - جامعة الموصل في نهاية شهر شباط (2013/2/18) وهي في

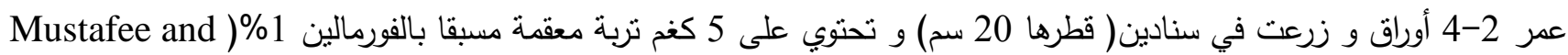
Chattopadhyay, 1981 و بمعدل نبات لكل سندانه. نركت النباتات في الحديقة الخلفية لقسم علوم الحياة و قسمت إلى 15 
مجموعة كل مجموعة تضم 5 سنادين ورشت النباتات بالمواد وكانت رشة واحدة في7 آذار 2013 و الرشة الثانية في 25 آذار 2013، نفذت تجربة عامليه وفق تصميم القطاعات العشوائية الكاملة وكمايلي:

$$
\begin{aligned}
& \text { 1 - - م رش النباتات بالماء فقط (المقارنة). }
\end{aligned}
$$

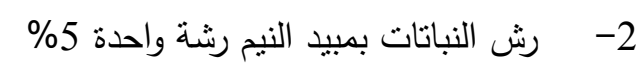

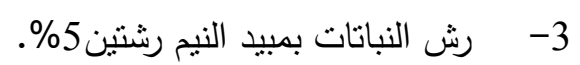

$$
\begin{aligned}
& \text { 4- رش النباتات مرة واحدة بالتراكيز } 1 \text { و } 5 \text { و } 10 \text { ملي مول من من حامض مض الساليسيليك. }
\end{aligned}
$$

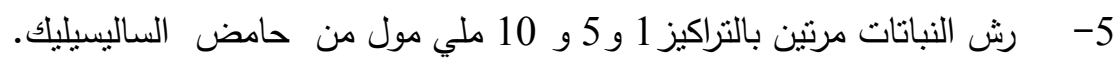

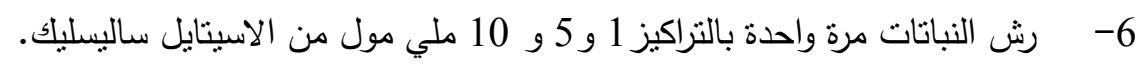

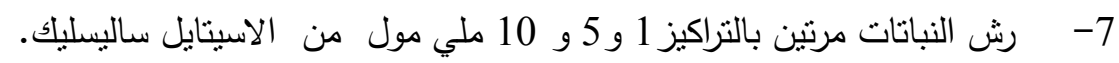

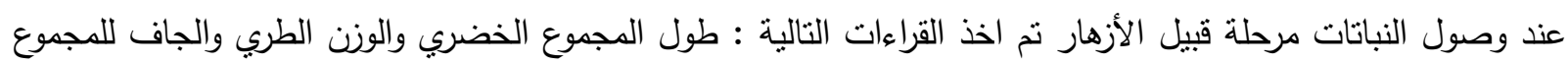
الخضري وقياس المحتوى النسبي للكلوروفيل وأنزيم البيروكسيديز و قياس أنزيم الفينيل الانين امونيا لاييز. حلت التبات النتائج إحصائيا

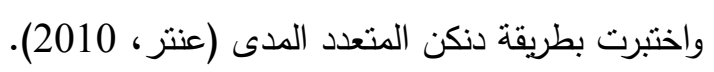

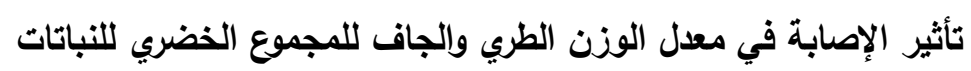
قلعت النباتات من السنادين ووضعت في أكياس نايلون ونقلت إلى المختبر وأزيلت التربة العالقة بها بوضعها تحت ماء ماء

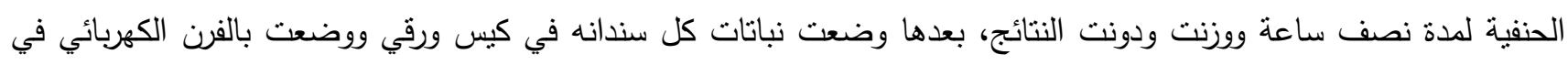

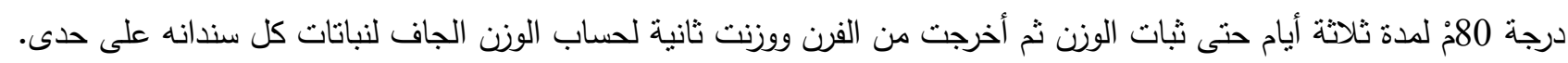
شدة الإصابة على أوراق نباتات الكلغان

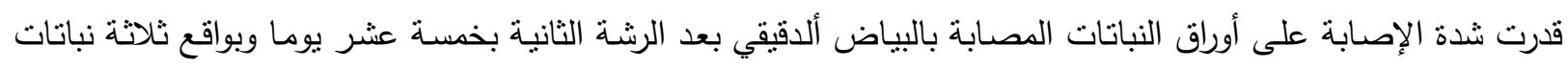
لكل مستوى وقدرت شدة الإصابة تبعا لطريقة (Clark,1975) إذ حصرت شدة الإصابة بمدى ينراوح بين (0-5) كالآتي: 0= النباتات سليمة وخالية من الإصابة.

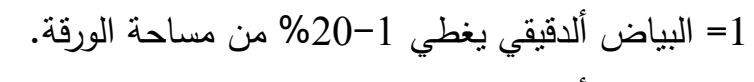
2= البياض ألدقيقي يغطي 21-40 \%

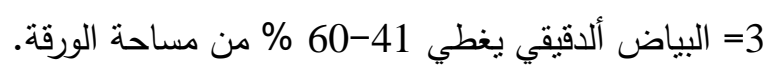

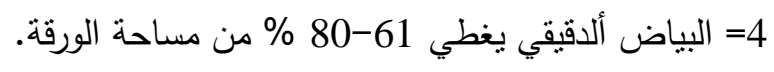

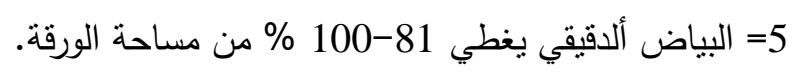
نم حساب شدة الإصابة على الأوراق تبعا لمعادلة (Vakalunakis,1990) وكما ليلي :

\section{عدد النباتات من الفئة الاولى × دليلها المرضي+ عدد النباتات من الفئة الثانية × دليلها المرضي + ....}

شدة الإصابة

$$
\text { العدد الكلي للنباتات × أعلى فئة }
$$

قياس الكلوروفيل

تم قياس المحتوى النسبي للكلوروفيل في اوراق نباتات الكلغان بواسطة الجهاز الحقلي(ب) Chlorophyll -Meter Spad-502 من أنتاج شركة Konica Minolta -Japan). و و بمعدل ثلاثة قراءات لكل نبات. قياس فعالية أنزيم البيروكسيديز(Peroxidase) 
اخذ 0.5 غم من الوريقات لكل معاملة وسحقت الوريقات مع 2 مل من المحلول المنظم الفوسفاتي ذي الأس الهيدروجيني 6

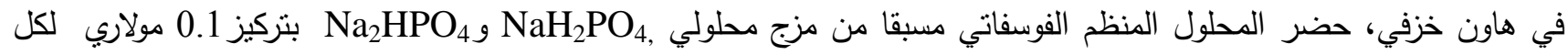
منهما ووضع المزيج في أنابيب اختبار سعة 10 مل، خضعت الأنابيب إلى عملية انتباذ بسرعة 4000 دورة/ دقيقة مدة 15 1دقيقة،

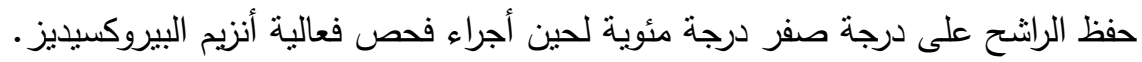

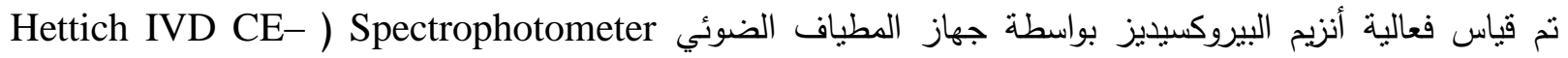
(Germany وذللك بوضع خليط مكون من 1مل من الراثح مع 1مل من بيروكسيد الهيدروجين بتركيز 20\% و 1مل من بن بuaiacol .(Houssien et al., 2010)

\section{قياس فعالية أنزيم الفينيل الانين امونيوم لاييز (PAL).}

حضر الراشح كما في الطريقة السابقة (قياس أنزيم البيروكسيديز) ونم قياس فعالية أنزيم PAL بوسطه جهاز الانين المطياف

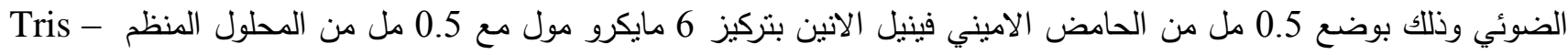

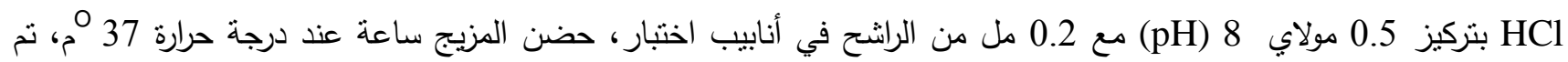
إيقاف التفاعل بإضافة 0.05 مل HCl بتركيز 5 عياري، ثم متابعة تغير اللون على طول موجي 290 نانوميتر بأخذ معدل 3 مكررات (Beavdoin-Eagan and Thorpe, 1985).

\section{النتائج و المناقشة}

اظهر الفحص ألمجهري ان المسبب المرضي للبياض ألدقيقي على الكلغان هو الفطر E.cichoracaerum وتبدأ الأعراض بالظهور في منتصف شهر آذار (الكوراني، 2006). تتثير النتائج إلى ان رش النباتات بالمبيد نيم (5\%) لم يكن له نأثير معنوي في زيادة نسبة الكلوروفيل ولكنه ادى الى خفض شدة ونسبة الاصابة الى 0.22 و50.0\% على التوالي (الجدول 1).

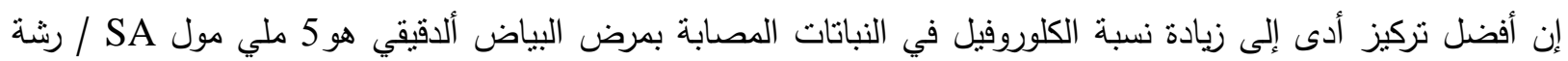

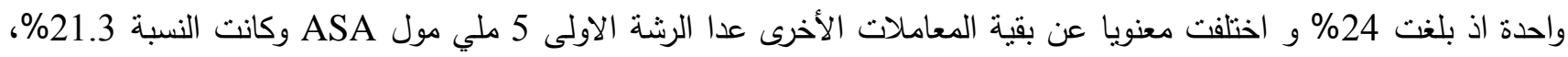
وكان التركيز 5 ملي مول SA رشة واحدة أفضل في حث المقاومة مما أدى إلى خفض شدة الإصابة إلى مثلى 0.2 وبنسبة انخفاض54.54\% (الجدول 2). نباتات الكلغان حساسة للإصابة بالفطر EAcichoracaerum المسبب لمرض واض البياض ألدقيقي والإصابة قد تصل إلى 100\% ومن النادر العثور في نهاية الموسم على نباتات سليمة من الإصابة (الكوراني، 2006). درس Achuo وآخرون (2004) نأثنير حامض الساليسليك في حث المقاومة ضد الفطر المسبب للبياض ألدقيقي في الطماطا والتبغ (Oidium neolycopersici) و وجد انه يعمل على تكوين مادة Benzothiadiazole (BTH) و التي تحث المقاومة ضد الفطر الممرض و اظهر الفحص ألمجهري أن مادة BTH تعمل على منع دخول الفطر إلى أوراق النباتات وبالتالي فثل ونل الإصابة أو تأخرها وأن معاملة التربة (ريا) أو الأوراق (رشا) بمادة BTH يحث مقاومة النباتات ضد الفطرة الفريات. و و يعد أنزيم الفينيل

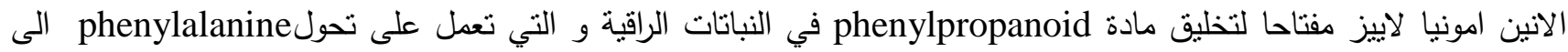
(Hahlbrock and phytoalexins g lignins و والذي يجز مواد بادئه trans-cinnamic acid .Scheel,1989) 
الجدول 1: تأثير الرش بحامض الساليسليك (SA) والاسيتايل ساليسليك (ASA) في المحتوى النسبي و شدة الاصابة لنباتات الكلغان المصابة بمرض البياض ألاقيقي.

\begin{tabular}{|c|c|c|c|c|c|}
\hline $\begin{array}{c}\text { لخفض شدة الإصابة } \\
\text { \% }\end{array}$ & شابة & المتلوى النسبي & التركيز & \multicolumn{2}{|c|}{ المعاملات } \\
\hline 0.0 & 0.44 & $* 4.3 \mathrm{de}$ & 0 & \multicolumn{2}{|c|}{ المقارنة (الماء) } \\
\hline 45.45 & 0.24 & $4.9 \mathrm{~d}$ & \multirow[t]{2}{*}{$\% 5$} & رشة واحدة & \multirow[t]{2}{*}{ المبيد نيم } \\
\hline 50.00 & 0.22 & $4.7 \mathrm{de}$ & & رشتين & \\
\hline 90.90 & 0.04 & $7.9 \mathrm{c}$ & 1مل مول & \multirow{3}{*}{ رشة واحدة } & \multirow{6}{*}{ SA } \\
\hline 95.54 & 0.2 & $24.0 \mathrm{a}$ & 5مل مول & & \\
\hline 90.90 & 0.04 & $1.2 \mathrm{f}$ & 10مل مول & & \\
\hline 40.90 & 0.26 & $8.5 \mathrm{c}$ & 1مل مول & \multirow{3}{*}{ رشتين } & \\
\hline 77.27 & 0.10 & $1.5 \mathrm{f}$ & 5 مل مول & & \\
\hline 72.72 & 0.12 & $2.0 \mathrm{f}$ & 10مل مول & & \\
\hline 86.36 & 0.06 & $8.9 \mathrm{c}$ & 1 مل مول & \multirow{3}{*}{ رشة واحدة } & \multirow{6}{*}{ ASA } \\
\hline 90.90 & 0.04 & $21.3 \mathrm{a}$ & 5 مل مول & & \\
\hline 90.90 & 0.04 & 3.0ef & 10 مل مول & & \\
\hline 45.45 & 0.24 & $14.2 \mathrm{~b}$ & 1 مل مول & \multirow{3}{*}{ رشتين } & \\
\hline 59.09 & 0.18 & $1.8 \mathrm{f}$ & 5 مل مول & & \\
\hline 68.18 & 0.14 & $2.0 \mathrm{f}$ & 10 مل مول & & \\
\hline
\end{tabular}

"المعاملات التي تحمل حروف متثابهة تدل على عدم وجود فروق معنوية عند مستوى احتمال 5\% حسب اختبار دنكن متعدد الحدود.

إن رش النباتات بحامض ASA و SA ادى الى زيادة نشاط أنزيم البيروكسيديز في أوراق نباتات الكلغان التي رشت مرتين بحامض ASA وبالتركيز 5 ملي مول (0.089) و بنسبة زيادة وصلت الى 60\% عن المقارنة (0.053) واختلف معنويا عن جميع المعاملات الأخرى (الجدول 3). تلعب مادة بيروكسيد الهيدروجين دورا مهما بشكل مباشر او غير مبرك مباشر في استحثناث المقاومة في

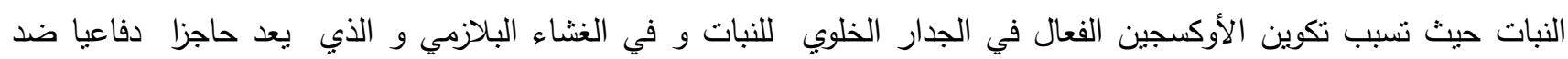
الفطريات الممرضة للنبات (Galal and Abdou,1996). أن أنزيمات البيروكسيز لا تشترك فقط بالبناء الحيوي للمركبات المضادة للميكروبات واللكنين ولكن أيضا تعمل منظم لجميع العمليات الايضية (Peng and Kuc, 1992). للبيروكسيديز دور في لانيات أكسدة الروابط العرضية بين التراكيب البروتينية الغنية بالحامض الاميني هيدروكسي برولين في الجدر الخلوية مما يجعل جدار الخلية أكثر مقاومة للتحلل بواسطة أنزيمات الميكروبات (Stermer and Hammerschmidt, 1987). 
الجدول 2: تأثير الرش بحامض الساليسليك (SA) والاسيتايل ساليسليك ( ASA) في ارتفاع النباتات وشدة إصابة نباتات

الكلغان بمرض البياض ألاقيقي.

\begin{tabular}{|c|c|c|c|c|c|}
\hline $\begin{array}{c}\text { ارتفاع النباتات } \\
\text { (سم) }\end{array}$ & الوزن الجاف & الوزن الرطب & (ملي مول) & \multicolumn{2}{|c|}{ المعاملات } \\
\hline $31.0 \mathrm{de}$ & $2.3 \mathrm{ab}$ & $* 2.2 \mathrm{f}$ & صفر & \multicolumn{2}{|c|}{ المقارنة (الماء) } \\
\hline $40.3 b c$ & $2.8 \mathrm{ab}$ & $6.8 \mathrm{~d}$ & \multirow[b]{2}{*}{$\% 5$} & رشة واحدة & \multirow{2}{*}{ العبيا نيم } \\
\hline $36,7 \mathrm{~cd}$ & $2.3 \mathrm{ab}$ & $7.8 \mathrm{~cd}$ & & رشتين & \\
\hline 32.0de & $3.4 a$ & $10.7 \mathrm{a}$ & 1 & \multirow{3}{*}{ رشة واحدة } & \multirow{6}{*}{$\mathbf{S A}$} \\
\hline $29.0 \mathrm{ef}$ & $2.1 \mathrm{ab}$ & $6.48 \mathrm{~d}$ & 5 & & \\
\hline $44.0 \mathrm{~b}$ & $2.4 \mathrm{ab}$ & $9.7 \mathrm{ab}$ & 10 & & \\
\hline $23.0 \mathrm{~g}$ & $1.2 \mathrm{~b}$ & $6.16 \mathrm{~d}$ & 1 & \multirow{3}{*}{ رشتين } & \\
\hline $33.0 \mathrm{de}$ & $1.9 \mathrm{ab}$ & $8.0 \mathrm{~cd}$ & 5 & & \\
\hline $25.0 \mathrm{fg}$ & $1.9 \mathrm{ab}$ & $6.69 \mathrm{~d}$ & 10 & & \\
\hline $30.0 \mathrm{e}$ & $1.9 \mathrm{ab}$ & 10.9 a & 1 & \multirow{3}{*}{ رشة واحدة } & \multirow{6}{*}{ ASA } \\
\hline 33.0de & $0.95 b$ & $4.3 \mathrm{e}$ & 5 & & \\
\hline $37.0 \mathrm{~cd}$ & $2.4 \mathrm{ab}$ & $8.8 \mathrm{bc}$ & 10 & & \\
\hline $43.0 \mathrm{~b}$ & $2.7 \mathrm{ab}$ & $7.0 \mathrm{~d}$ & 1 & \multirow{3}{*}{ رشتين } & \\
\hline $52.0 \mathrm{a}$ & $0.9 \mathrm{~b}$ & $6.1 \mathrm{~d}$ & 5 & & \\
\hline $33.0 \mathrm{de}$ & $2.8 \mathrm{ab}$ & $9.3 \mathrm{bc}$ & 10 & & \\
\hline
\end{tabular}

*المعاملات التي تحمل حروف منثابهة تدل على عدم وجود فروق معنوية عند مستوى احتمال 5\% حسب اختبار دنكن متعدد الحدود.

ووجد ان رش نباتات الكلغان بحامض الساليسليك ادى الى زيادة نشاط أنزيم الفينيل الانين امونيا لاييز (PAL) وقد وصلت الى 0.62 ( الشكل 1) في النباتات التي رشت مرنين و بالتركيز 5 ملي مول حامض اسيتايل الساليسليك (53\%) و ولنيات

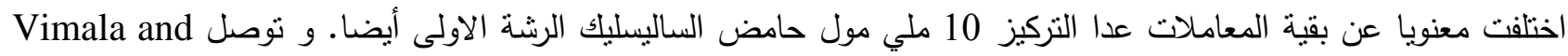
ف Suriachandraselvan في نباتات الباميا Okra) المصابة بالفطر E.cichoracearum. يتضح مما سبق ان رش النباتات مرة واحدة بتركيز 5 ملي مول حامض اسيتايل ساليسليك ادى الى حث المقاومة المكتسبة في نبات الكلغان ضد الاصابة الفطر المسبب لمرض البياض الدقيقي كما ادى الى زيادة الوزن الطري والجاف وارتفاع النباتات وخفض شدة الإصابة. 
الجدول 3: تأثير الرش بحامض الساليسليك (SA) والاسيتايل ساليسليك (ASA) على نشاط أنزيم البيروكسيديز في نباتات الكلغان المعرضة للإصابة بمرض البياض ألاقيقي.

\begin{tabular}{|c|c|c|c|}
\hline المعدل & التركيز (ملي مول) & \multicolumn{2}{|c|}{ المعاملات } \\
\hline *0.053cde & 0 & \multicolumn{2}{|c|}{ المقارنة } \\
\hline $0.019 \mathrm{f}$ & \multirow[t]{2}{*}{$\% 5$} & رشة واحدة & \multirow[t]{2}{*}{ بالمبيد نيم } \\
\hline 0.031 ef & & رشتين & \\
\hline $0.058 \mathrm{cde}$ & 1 & \multirow{3}{*}{ رشة واحدة } & \multirow{6}{*}{ SA } \\
\hline 0.034 ef & 5 & & \\
\hline $0.039 \mathrm{def}$ & 10 & & \\
\hline $0.038 \mathrm{def}$ & 1 & \multirow{3}{*}{ رشتين } & \\
\hline $0.022 \mathrm{f}$ & 5 & & \\
\hline $0.053 \mathrm{cde}$ & 10 & & \\
\hline $0.069 \mathrm{bc}$ & 1 & \multirow[b]{3}{*}{ رشة واحدة } & \multirow{6}{*}{ ASA } \\
\hline $0.062 \mathrm{~cd}$ & 5 & & \\
\hline 0.027 ef & 10 & & \\
\hline $0.051 \mathrm{cde}$ & 1 & \multirow{3}{*}{ رشتين } & \\
\hline 0.089 a & 5 & & \\
\hline $0.067 \mathrm{bc}$ & 10 & & \\
\hline
\end{tabular}

"المعاملات التي تحمل حروف منتابهة تدل على عدم وجود فروق معنوية عند مستوى احتمال 5\% حسب اختبار دنكن متعدد الحدود. وحدة الأنزيم : كمية الأنزيم الني تعمل على تكوين ملي مول واحد من الناتج / دقيقة .

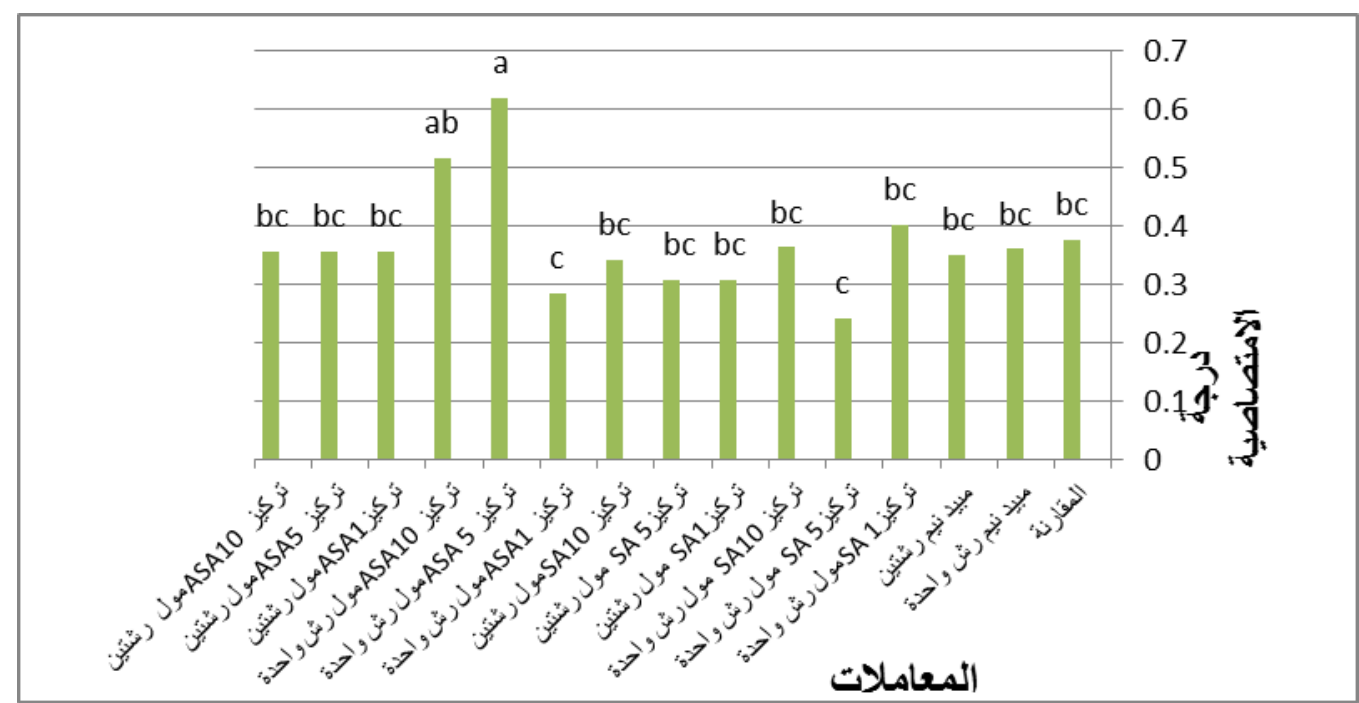

الثكل 1: تأثير الرش بحامض الساليسليك (SA) والاسيتايل ساليسليك (ASA) في نشاط الفينيل الانين امونيا لاييز في نباتات الكلغان المعرضة للإصابة بمرض البياض ألاقيقي. المصادر العربية

عنتر ، سالم حمادي(2010). التحليل الإحصائي في البحث العلمي و برنامج SAS. دار ابن الأثثر للطباعة و النشر. جامعة الموصل.

الكوراني، رمضان يوسف (2006). دراسة أمراض البياض ألدقيقي في حقول محافظات شمال العراق. رسالة دكتوراه، كلية العلوم، جامعة الموصل. 
طه، هبة هادي؛ رمضان، نديم احمد (2013) حث مقاومة نباتات الباقلاء لفطر Alternaria alternata باستخدام فوسفات

البوتاسيوم و بيروكسيد الهيدروجين. مقبول للنشر في مجلة علوم الرافدين 2013.

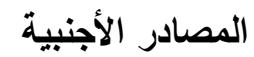

Achuo, E.A.; Audenaert, K.; Meziane, H.; Höfte, M. (2004). The salicylic acid-dependent defense pathway is effective against different pathogens in tomato and tobacco. Plant Pathology. 53, $65-72$.

Amadioha A.C. (2000). Controlling rice blast in vitro and in vivo with extracts of Azadirachta indica. Crop Protect. 19, 287-290.

Beavdoin-Eagan, L.D.; Thorpe, T.A. (1985). Tyrosine and phenyl alanine ammonia lyase activities during shoot initiation in tobacco callus. Plant Physiol.,78,438 -41

Clark, R.L. (1975). Powdery mildew resistance in plant introduction of cucumber in Iowa. Pl. Dis. Repter., 59, 1024-1028.

Delaney, T.P. (1997). Genetic dissection of acquired resistance to disease. Plant Physiol, 113, 5-2.

Eppler, A. (1995). Effects on viruses and organisms. In: Schmutterer، H.(ed.),The Neem Tree. Sources of Unique Natural Products for Integrated Pest Management, medicine Industry and Other Purposes. pp. 93-117. Weinheim، New York, Basel, Cambridge, Tokyo: VCH.

Galal, A.A.; Abdou, El.S. (1996). Antioxidants for the control of fusarial disease in cowpea. Egypt. J. Phytopathol., 24,1-12.

Hahlbrock, K.; Scheel, D.(1989). Physiology and molecular biology of phenylpropanoid metabolism. Ann. Rev. Plant Physiol. Plant, Mol. Bio. 40, 347-369.

Houssien, A.A.; Ahmed, S.M.; Ismail, A.A. (2010). Activation of tomato plant defense response against Fusarium wilt disease using Trichoderma harzianum and Salicylic acid under greenhouse conditions. J. Agric. and Bio. Sci.,6, 328-338.

Maleck, K.; Levine, A.; Eulgem, T. (2000).The transcriptome of Arabidopsis thaliana during systemic acquired resistance. Nat. Genetics, 26,403-410.

Maria, J.G.; Martínez-Merino, V. (2007). Determination of the free salicylic acid concentration in aspirin by forming $\mathrm{fe}^{+3}$ complexes. Exercise I.11 .merino @unavarra .es.www.iupac. org/publications /cd/medicinal chemistry/.

Mustafee, T.P.; Chattopadhyay, S.B. (1981). Fungicide control of soil inhibiting pathogens. Pesticides 15,29-31.

Peng, M.; Kuc, J. (1992). Peroxides-generated hydrogen peroxide as a source of antifungal activity in vitro and on tobacco leaf disks. Phytopathology, 82,696-99.

Porter, B. (2003). Milk thistle production in Saskatchewan, Saskatchewan Agriculture, Food and Rural Revitalization. Http://www.agr.gov. sk.ca /docs /crops/special crops /production infor.

Singh, UP.; Prithiviraj (1997). Neemazal, a product of neem (Azadirachta indica), induces resistance in pea (Pisum sativum) against Erysiphe pisi. Physiol. Mol. Plant Pathol. 51,181-194.

Stermer, B.A.; Hammerschmidt, R. (1987). Association of heat shock induced resistance to disease with increased accumulation of insoluble extension and ethylene synthesis. Physiol. Mol. Plant Pathol., 31, 239-249.

Vakalunakis, D.J. (1990). Host range of Alternatia alternata f. sp. cucurbitae causing leaf spot of cucumber. Plant Dis., 84, 27 -30.

Vimala, R.; Suriachandraselvan, M. (2000). Induced resistance in bhendi against powdery mildew by foliar application of salicylic acid. J. Biopesticides, 2(1), 111-114. 